\title{
François Hédelin, abbé d'Aubignac, Des satyres brutes, monstres et démons
}

\section{Benedetta Papasogli}

\section{Q OpenEdition}

1 Journals

\section{Edizione digitale}

URL: https://journals.openedition.org/studifrancesi/40627

DOI: 10.4000/studifrancesi.40627

ISSN: 2421-5856

\section{Editore}

Rosenberg \& Sellier

\section{Edizione cartacea}

Data di pubblicazione: 1 juillet 2004

Paginazione: 184-185

ISSN: 0039-2944

\section{Notizia bibliografica digitale}

Benedetta Papasogli, «François Hédelin, abbé d'Aubignac, Des satyres brutes, monstres et démons», Studi Francesi [Online], 142 (XLVIII | I) | 2004, online dal 30 novembre 2015, consultato il 09 septembre 2021. URL: http://journals.openedition.org/studifrancesi/40627 ; DOI: https://doi.org/10.4000/ studifrancesi.40627

Questo documento è stato generato automaticamente il 9 septembre 2021.

\section{(c)}

Studi Francesi è distribuita con Licenza Creative Commons Attribuzione - Non commerciale - Non opere derivate 4.0 Internazionale. 


\title{
François Hédelin, abbé d'Aubignac, Des satyres brutes, monstres et démons
}

\author{
Benedetta Papasogli
}

\section{NOTIZIA}

FRANÇoIS HÉDELIN, abbé d'Aubignac, Des satyres brutes, monstres et démons, texte établi, présenté et annoté par GILLES BANDERIER, Grenoble, Jérôme Millon, 2003, pp. 222.

1 La collana «Atopia» dell'editore di Grenoble ha proposto negli anni, un po' alla rinfusa, gioielli della tradizione mistica e testimonianze rare e strane di un irrazionalismo che sempre più si conferma come il permanente lato d'ombra della cultura secentesca. Davvero rara e pochissimo nota, rappresentata in una sola edizione secentesca (1627) e in una sola riedizione alla fine dell'Ottocento, questa operetta giovanile dell'abbé d'Aubignac. Prima di occuparsi di teatro, di dissertare pro e contro Corneille, e di lasciare un segno nella storia del genere narrativo con il suo Roman des lettres, François Hédelin aveva concepito un vasto progetto di cui dà notizia nell'avertissement dell'opera che presentiamo. Sarebbe stato, per dirla con un titolo di Borges, un «libro degli esseri immaginari», ove con l'ausilio di molta erudizione, una discreta ragionevolezza cartesiana, e una misura di teologia, ci avrebbe parlato di «Hippocentaures, Tritons, Néréides, Géants, Pygmées, Acéphales, Arimaspes, Hommes colorés». Si sarebbe confrontato insomma con quei «monstres et prodiges» su cui già il XVI secolo aveva operato una riduzione naturalistica e sulla cui possibilità e ragione di essere continua a interrogarsi seriamente il pensiero dell'età classica. Per ora l'abatino di ventitré anni s'impegna in una tesi che, come egli la enuncia, con la forza perentoria della sua giovanile erudizione, ha del ragionevole e dell'assurdo: i satiri non sono uomini. Accuratamente vengono distinti in bestie («brutes»), in esseri ibridi nati da accoppiamenti mostruosi («monstres»), in manifestazioni diaboliche («démons»). La riduzione naturalistica o teologica non impedisce il libero galoppo dell'immaginazione attraverso testi classici e cristiani e mitologie di religioni diverse, avvicinate tra loro con un abbozzo di metodo comparatistico che porta talora a suggestive letture 
simboliche. Sulla testimonianza di innumerevoli «fables», ivi compreso un curiosissimo passo della vita di Paolo di Tebe scritta da S. Gerolamo e tradotta da Arnauld d'Andilly, d'Aubignac cerca criteri analitici da applicare alla conoscenza di fenomeni che mai la sua mente aperta - per posizione storica, per identità religiosa - alla ragione e al mistero è tentata di giudicare inesistenti.

2 Il curatore dell'edizione non ha abbondato negli apparati critici. L'introduzione, l'annotazione, la bibliografia sono funzionali a una buona lettura del testo più che a un suo studio contestualizzato. L'opera di d'Aubignac sottintende un così folto entroterra di rimandi letterari e di curiosità libresche che s'impone un'edizione colta, qual è quella che presentiamo: ma, ricordiamolo, «Atopia», la collana che lo accoglie, punta meno sulla presentazione scientifica e più sull'originalità della cernita, sulla strana fragranza dei testi ritrovati. 